\title{
Use of SGLT-2 inhibitors in the treatment of type 2 diabetes mellitus
}

\author{
Leyna Leite Santos $^{1 *}$, Fernando José Camello de Lima ${ }^{2}$, Célıo Fernando de Sousa-Rodrigues ${ }^{3}$, Fabiano Timbó Barbosa ${ }^{4}$ \\ ${ }^{1}$ Full Professor of Propedeutics, Centro de Estudos Superiores de Maceió, Maceió, AL, Brazil \\ ${ }^{2}$ MSc in Health Sciences. Assistant Professor of Anatomy, Universidade Federal de Alagoas (Ufal), Maceió, AL, Brazil \\ ${ }^{3} \mathrm{PhD}$ in Science. Associate Professor IV of Anatomy, Ufal, and Adjunct Professor, Universidade Estadual de Ciências da Saúde de Alagoas (Uncisal), Maceió, AL, Brazil \\ ${ }^{4} \mathrm{PhD}$ in Health Sciences. Adjunct Professor of Basics of Surgical and Anesthetic Technique, Ufal, Maceió, AL, Brazil
}

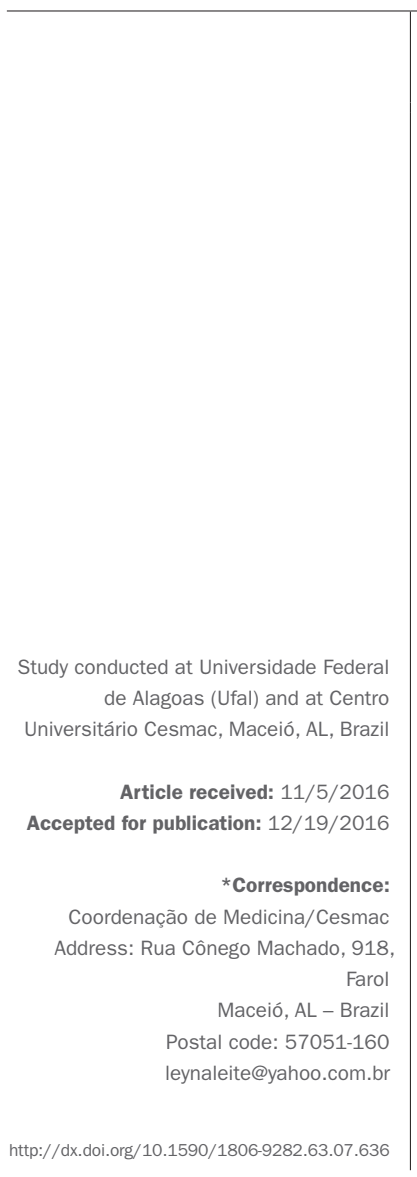

\section{SUMMARY}

Introduction: Diabetes mellitus is one of the most common chronic diseases in the world, with high morbidity and mortality rates, resulting in a greatly negative socioeconomic impact. Although there are several classes of oral antidiabetic agents, most of the patients are outside the therapeutic goal range. Objective: To review the use of SGLT- 2 inhibitors in the treatment of type 2 diabetes mellitus, focusing on their favorable and unfavorable effects, as well as on cardiovascular profile.

Method: A literature search on Pubmed database was performed using the following keywords: "SGLT-2 inhibitors," "dapagliflozin,” "empagliflozin,” "canagliflozin." Results: SGLT-2 inhibitors are a class of oral antidiabetic drugs directed to the kidney. Their mechanism of action is to reduce blood glucose by inducing glycosuria. Extra-glycemic benefits have been described, such as weight loss, decline in blood pressure and levels of triglycerides and uric acid, and they can slow the progression of kidney disease. Genitourinary infections are the main side effects. There is a low risk of hypotension and hypoglycemia. Diabetic ketoacidosis is a serious adverse effect, although rare. Empagliflozin has already had its cardiovascular benefit demonstrated and studies with other drugs are currently being performed.

Conclusion: SGLT-2 inhibitors are a new treatment option for type 2 diabetes mellitus, acting independently of insulin. They have potential benefits other than the reduction of blood glucose, but also carry a risk for adverse effects.

Keywords: SGLT-2 inhibitors, type 2 diabetes mellitus, kidney, glycosuria, review.

\section{INTRODUCTION}

Diabetes mellitus (DM) is currently considered a public health problem, with increasing incidence and prevalence worldwide. The global estimate of DM patients in 2013 was greater than 381 million, projected to increase to approximately 592 million by $2035 .^{1,2}$ Type 2 diabetes mellitus (T2DM) is one of the most common metabolic disorders, accounting for $90-95 \%$ of adult diabetes. ${ }^{3}$

The pathophysiology of T2DM is complex and multifactorial. Ralph DeFronzo was responsible for the concept of ominous octet - a broader theory, which identified different organs in addition to the pancreas, as well as eight problems, which play a key role in the pathogenesis of T2DM. The main defects include pancreatic beta cell failure and insulin resistance in muscles and liver. Furthermore, incretin deficiency, accelerated lipolysis, hyper- glucagonemia, insulin resistance in the brain, and increased renal reabsorption of glucose also participate in the development of the disease ${ }^{4}$ (Table 1).

\section{TABLE 1 DeFronzo's ominous octet.}

\begin{tabular}{ll} 
Pancreatic beta cells & Insufficient insulin secretion \\
\hline Pancreatic alpha cells & Excess glucagon \\
\hline Fat cells & Increased lipolysis \\
\hline Muscles & Reduction of peripheral glucose uptake \\
\hline Liver & Greater hepatic glucose production \\
\hline Gastrointestinal tract & Decline of incretin activity \\
\hline Brain & Dysfunction of brain \\
& neurotransmitters \\
\hline Kidneys & Greater renal reabsorption of glucose \\
\hline
\end{tabular}


The identification of the ominous octet was important, as it provided a paradigm shift in the treatment of DM. DeFronzo proposed the association of drugs to act in all pathophysiological defects of the disease, and not only reduce glycated hemoglobin. ${ }^{4}$ Although there are several therapeutic options, it is still common to find poorly controlled patients with blood glucose levels outside of the target range. One of the causes that contribute to this is therapeutic inertia of physicians, who end up delaying the association of drugs. ${ }^{5}$

Complementing the therapeutic arsenal currently available for the treatment of T2DM, a new class of drugs called SGLT-2 inhibitors has been approved in recent years by the Brazilian Agency for Sanitary Surveillance (Anvisa, in the Portuguese acronym), with a focus on kidney treatment. They reduce blood glucose by increasing the urinary excretion of excess glucose that would be reabsorbed by the kidneys. ${ }^{6}$

The aim of this article was to review the state of the use of SGLT-2 inhibitors in the treatment of T2DM, focusing on its favorable and unfavorable effects, and its cardiovascular profile.

\section{Method}

Bibliographical and transversal search for scientific articles was carried out in the Pubmed (National Center for Biotechnology Information) database. The following keywords were used: "SGLT-2 inhibitors," "dapagliflozin," “empagliflozin," "canagliflozin". The inclusion criteria were: scientific articles in human beings or animals, written in English, Portuguese or Spanish. There was no date restriction for the articles. Scientific articles related to the subject were selected after title and abstract analysis. Articles such as letters to the editor, communications, editorials, comments, articles in other languages and those with partially published data were excluded. The references of the articles selected were also analyzed to identify other articles relevant to the subject.

\section{THE KIDNEY AS A TREATMENT TARGET}

The kidney contributes to glucose homeostasis by filtering plasma glucose through glomeruli and reabsorbing it in the segments 1 (S1) (90\%) and 3 (S3) (10\%) of the proximal tubule. In healthy subjects, the kidneys filter approximately $180 \mathrm{~g}$ of glucose per day. Due to reabsorption, glucose in the urine is either absent or present at very low concentrations $\left(0.03\right.$ to $0.30 \mathrm{~g} / \mathrm{dL}$ ). ${ }^{7,8}$

The sodium and glucose linked transporter (SGLT) is a sodium/glucose cotransporter membrane protein. Type 2 (SGLT-2) is present in S1 of the proximal convoluted tubule and is the main glucose transporter, where- as type 1 is found in $\mathrm{S} 3$ of the proximal convoluted tubule and the small intestine. ${ }^{6,9}$

That is why, in recent years, the kidney has become a target organ for the treatment of DM. The class of SGLT-2 inhibitors (SGLTi-2), approved for T2DM, then emerged. SGLT-2 inhibitors, by inhibiting glucose reabsorption in the kidneys, increase urinary glucose excretion, reducing glycemic levels (Figure 1) in an insulin-independent manner, with positive effects on various glycemic parameters, such as glycated hemoglobin, fasting and postprandial levels of blood sugar. ${ }^{10-12}$ They can then be used at any stage of the disease in both newly diagnosed and long-term diabetes, ${ }^{13}$ since they do not depend on insulin secretion or peripheral insulin sensitivity. ${ }^{14}$

Three drugs have been approved in Brazil by the regulatory agency Anvisa: dapagliflozin, empagliflozin and canagliflozin (Table 2). These drugs can be used both as monotherapy or combined with other oral antidiabetic drugs (OAD) or insulin. ${ }^{12}$ Dapagliflozin and empagliflozin have a greater sensitivity for SGLT-2, while canagliflozin is the only one that has a significant effect on SGLT-1, but only at high doses (greater than $200 \mathrm{mg}$ ). For this reason, it has been suggested that canagliflozin can reduce the levels of blood glucose by double action, both in the kidneys and in the intestine. ${ }^{15}$ Nevertheless, more studies are needed to confirm this hypothesis.

TABLE 2 SGLT-2 inhibitors.

\begin{tabular}{lll} 
Active ingredient & Comercial name & Presentation \\
\hline Canagliflozin & Invokana ${ }^{\circledR}$ & 100 and $300 \mathrm{mg}$ \\
\hline Dapagliflozin & Forxiga ${ }^{\circledR}$ & $10 \mathrm{mg}$ \\
\hline Empagliflozin & Jardiance ${ }^{\circledR}$ & 10 and $25 \mathrm{mg}$ \\
\hline
\end{tabular}

SGLT-2 inhibitors have demonstrated several beneficial extra-glycemic effects in patients with DM. Just like any other drug, they present risks and side effects that should not be overlooked.

\section{Positive effects of SGLTi-2}

Several studies have already shown that SGLTi-2 can reduce body weight in patients with T2DM, since the elimination of glucose through urine leads to a loss of calories (around 200-300 cal/day), resulting in a negative energy balance. ${ }^{16-18} \mathrm{~A}$ study with dapagliflozin showed a significant reduction in waist circumference, which is consistent with a reduction in fat mass. ${ }^{19}$ Studies evaluating body composition suggested that most of the weight loss associated with SGLTi-2 was due to a reduction in visceral or subcutaneous fat. ${ }^{20,21}$ This is a beneficial effect for dia- 


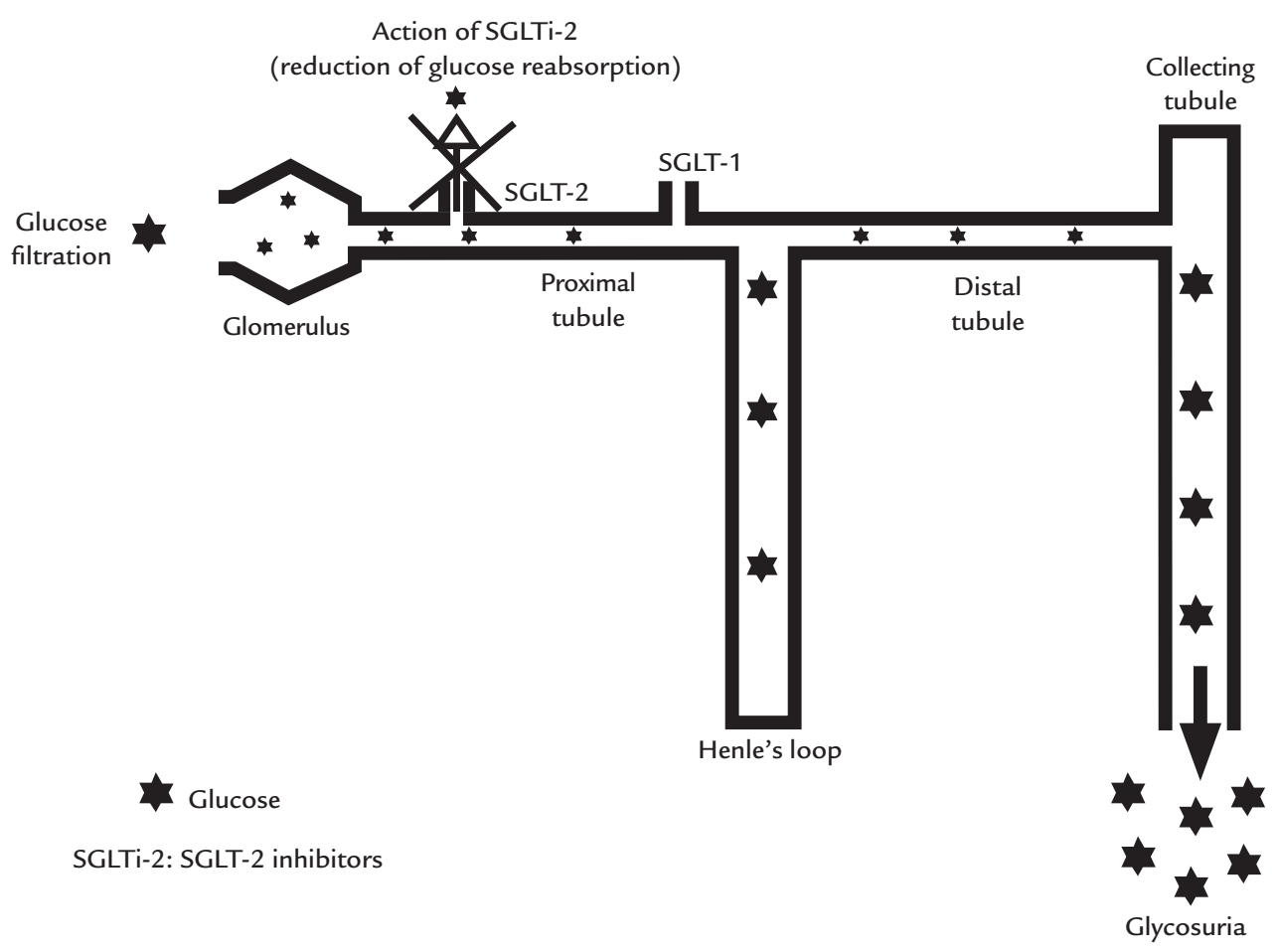

FIGURE 1 Action of SGLT-2 inhibitors.

betic patients, since most are overweight and thus present greater insulin resistance. In addition, these drugs differ from other OADs, such as sulfonylurea and insulin, which cause weight gain. ${ }^{22}$

Decreased blood pressure (BP), both systolic (SBP) and diastolic (DBP), was observed with SGLTi-2, without compensatory increase in heart rate. This is because, by causing glycosuria, osmotic diuresis occurs, reducing circulating volume and, consequently, BP levels. Weight reduction and sodium depletion also contribute to this finding. ${ }^{23,24}$ In addition, a direct vascular effect, with reduced arterial stiffness, leads to BP change. ${ }^{25}$

The effect of this class on serum lipid levels is mild. Small increase in HDL and LDL levels, but no change in HDL/LDL ratio and a mild reduction in triglyceride levels were found in clinical trials. It is not yet known if these changes are clinically relevant, and further studies are needed on the subject. ${ }^{19,24}$

$\mathrm{DM}$ is a major risk factor for cardiovascular disease (CVD) and CVD is the leading cause of morbidity and mortality in diabetics. ${ }^{26} \mathrm{It}$ is also known that DM is one of the main risk factors responsible for cognitive deficits, such as Alzheimer's disease and vascular dementia. ${ }^{27}$
In a study of obese diabetic rats, administration of empagliflozin was able to significantly improve cardiac fibrosis and inflammation, coronary artery remodeling, vascular dysfunction, and cognitive dysfunction. These benefits were associated with significant attenuation of oxidative stress in cardiovascular and brain tissues. ${ }^{28}$

Uric acid is the end product of purine metabolism. Hyperuricemia, in addition to causing gout, is associated with chronic kidney disease, DM and metabolic syndrome, and is considered a marker of cardiovascular (CV) risk. Reduction of serum uric acid levels has been seen with SGLTi-2 due to increased urinary excretion. ${ }^{29,30}$ No increase in kidney uric acid stones was observed with SGLTi-2. ${ }^{30}$

This new class of drugs has already been shown to reduce glycemic levels in animals and humans with type $1 \mathrm{DM}$ (T1DM), in addition to allowing a reduction in insulin dosage. ${ }^{31-33}$ These drugs could, thus, be used as an adjuvant therapy in the treatment of DM1, with low risk of hypoglycemia and without weight gain. However, this is not yet an approved therapy for T1DM, and further studies are needed to assess the safety of SGLTi-2 in this group of patients. ${ }^{33}$ 
Studies in animal and human models have demonstrated that the use of SGLTi-2 has improved markers of renal damage, such as albuminuria, hyperfiltration/hypertrophy, inflammation and expansion of the mesangial matrix, suggesting the possibility of preventing diabetic nephropathy. There can be a slight reduction in glomerular filtration rate at the onset of use, which normalizes after a few weeks. ${ }^{34,35} \mathrm{~A}$ large study with empagliflozin combined with standard treatment in patients at high $\mathrm{CV}$ risk showed an improvement in the progression of kidney disease compared to placebo. ${ }^{36}$ Since the drug's effect depends on renal function, its benefits will be reduced in patients with this type of dysfunction. ${ }^{37}$

\section{Negative effects OF SGLTi-2}

There is a risk of hypoglycemia with SGLTi-2, but at a lower rate. Such a low risk is justified by the fact that these drugs have an insulin-independent mechanism of action. The risk increases when these drugs are associated with insulin or insulin secretagogues. ${ }^{13}$

The main side effects related to the class are urinary and genital infections (vaginal moniliasis, vulvovaginitis, balanitis), attributed to the higher concentration of glucose in the urine. Infections are usually resolved with conventional treatments. ${ }^{17}$ In order to avoid such complications, it is recommended to instruct patients about proper hygiene.

Osmotic diuresis caused by SGLTi- 2 is responsible for the small rise in hematocrit levels, due to hemoconcentration, but without significant clinical effect verified so far. ${ }^{13}$

The risk of systemic arterial hypotension is low, since the reduction of SBP and DBP is not as marked. SGLTi-2 may increase the effect of thiazide diuretics and loop diuretics, with increased risk of dehydration. Greater attention should be given to the elderly, who are more sensitive to the risk of hypotension, especially those who use diuretics. ${ }^{23,24}$

A more serious and potentially fatal but uncommon adverse effect is the risk of diabetic ketoacidosis (DKA), rare in T2DM but more common in T1DM. These drugs are being used in addition to what has been approved by Anvisa, as an adjunct to insulin treatment in T1DM. There have been reports of atypical presentation, with mild increase in blood glucose and even normoglycemic DKA. This may delay diagnosis and treatment, and thus compromise the patient's prognosis. Some cases were secondary to the occurrence of triggers, such as infection, reduction of water intake or low adherence to insulin therapy. The mechanism involved in this situation is not yet known. If DKA is suspected, the drug must be discontinued immediately, ketone levels should be investigated and appropriate treatment initiated. ${ }^{38,39}$
Canagliflozin was associated with another side effect: bone fracture. A study with this drug demonstrated a significant decline of bone mineral density (BMD) in the hip, raising the hypothesis that it would be secondary to weight loss. ${ }^{40}$ Reducing BMD can accelerate the osteoporosis process and increase the risk of fractures. ${ }^{41}$ More studies are needed for a more detailed investigation of this risk.

\section{Cardiovascular profile}

In recent years, for new OADs to be registered and maintain such approval, drug regulatory agencies now require a CV safety study in patients at high risk. ${ }^{42}$ The least expected is that it has a neutral effect over placebo. ${ }^{43,44}$

The results of the EMPA-REG OUTCOME study were published in September 2015 at the $51^{\text {st }}$ Congress of the European Association for the Study of Diabetes (EASD), which was considered a positive milestone in the history of DM, as the first study to demonstrate cardiovascular superiority with an OAD. ${ }^{45}$

This was a randomized, multicenter, double-blind, placebo-controlled trial that evaluated the effects of standard treatment-associated empagliflozin on the occurrence of $\mathrm{CV}$ events. The study included more than 7,000 individuals with T2DM and CVD, either treated or being treated, for a mean period of 3.1 years. There was a significant reduction in the risk of major $\mathrm{CV}$ events (CV death, non-fatal acute myocardial infarction [AMI] and non-fatal stroke) by $14 \%$. There was also a significant decrease in CV death rate (38\%), in the rate of hospitalization due to heart failure (35\%) and death from any cause (32\%). ${ }^{45}$

Other effects were found in this study, including reductions in weight and waist circumference, decrease in uric acid levels, decrease in SBP and DBP without any increase in heart rate, and modest increases in LDL and HDL cholesterol..$^{45}$ It is not yet known, however, what mechanism provided such benefit. It may have been a multifactorial effect that included an osmotic diuretic factor, a lower rate of hypoglycemia, good cardiac performance (BP decline without tachycardia), change in arterial stiffness, weight loss, and reduction in albuminuria and uricemia. ${ }^{43,45}$

Further studies are underway to show the $\mathrm{CV}$ profile of the other SGLTi-2. These are: the Canagliflozin Cardiovascular Assessment (CANVAS) and the Dapagliflozin Effect on Cardiovascular Events (DECLARE-TIMI 58). They will clarify whether this CV benefit is a class effect or restricted to empagliflozin, and may contribute by providing more information regarding this new class. ${ }^{43}$ 


\section{FinAL REMARKS}

Although there are several drugs available to treat DM, glycemic control is still not ideal and leads to a significant increase in morbidity and mortality.

SGLTi-2 are the latest oral agents for lowering blood sugar levels, targeting the kidneys, causing glycosuria. They offer the potential to improve glycemic control with a low risk of hypoglycemia, regardless of insulin secretion. These drugs have several favorable effects, such as reductions in weight, BP, uric acid and triglyceride, in addition to reducing the progression of kidney disease, and a proven $\mathrm{CV}$ benefit for empagliflozin. Its main adverse effects are: more frequent genitourinary infections, low risk of hypotension, and rare and severe risk of DKA. There is much more to be uncovered about this class of drugs, with promising prospects for the history of diabetes.

\section{Conflict of Interest}

The authors declare no conflict of interest.

\section{Resumo}

Uso dos inibidores da SGLT-2 no tratamento do diabetes mellitus tipo 2

Introdução: $\mathrm{O}$ diabetes mellitus é uma das doenças crônicas mais frequentes no mundo, com altas taxas de morbimortalidade, resultando em um grande impacto negativo socioeconômico. Apesar de existirem diversas classes de antidiabéticos orais, a maioria dos pacientes acometidos está fora da meta terapêutica.

Objetivo: Revisar o uso dos inibidores da SGLT-2 no tratamento do diabetes mellitus tipo 2 , com enfoque nos efeitos favoráveis, desfavoráveis e no perfil cardiovascular.

Método: Foi realizada uma pesquisa bibliográfica transversal com artigos científicos obtidos da base de dados Pubmed, utilizando os descritores: "SGLT-2 inhibitors", "dapagliflozin”, "empagliflozin”, "canagliflozin”.

Resultados: Os inibidores da SGLT-2 são uma classe de antidiabéticos orais com atuação no rim. O mecanismo de ação é reduzir a glicemia induzindo glicosúria. Benefícios extraglicêmicos já foram descritos, como redução de peso, pressão arterial, triglicerídeos e ácido úrico, além de retardar a progressão da doença renal. O principal efeito colateral é a infecção geniturinária, com baixo risco de hipotensão e hipoglicemia. Cetoacidose diabética é um efeito adverso grave, mas infrequente. A empagliflozina já teve seu benefício cardiovascular demonstrado, e estudos com outras drogas estão em andamento.
Conclusão: Os inibidores da SGLT-2 são uma nova opção de tratamento do diabetes mellitus tipo 2 , que atua de forma insulino-independente e com potenciais benefícios adicionais, além da redução da glicemia, mas também com risco de efeitos adversos.

Palavras-chave: inibidores da SGLT-2, diabetes mellitus tipo 2, rim, glicosúria, revisão.

\section{References}

1. Guariguata L, Whiting DR, Hambleton I, Beagley J, Linnenkamp U, Shaw JE. Global estimates of the prevalence of diabetes for 2013 and projections for 2035 for the IDF Diabetes Atlas. Diabetes Res Clin Pract. 2014; 103(2):137-49.

2. Wild S, Roglic G, Green A, Sicree R, King H. Global prevalence of diabetes: estimates for the year 2000 and projections for 2030. Diabetes Care. 2004; 27(5):1047-53

3. Bailey RA, Damaraju CV, Martin SC, Meininger GE, Rupnow MFT, Blonde L. Attainment of diabetes-related quality measures with canagliflozin versus sitagliptin. Am J Manag Care. 2014; 20(1 Suppl):S16-24.

4. DeFronzo RA. From the triumvirate to the ominous octet: a new paradigm for the treatment of type 2 diabetes mellitus. Diabetes. 2009; 58(4):773-95

5. Grant R, Adams AS, Trinacty CM, Zhang F, Kleinman K, Soumerai SB, et al. Relationship between patient medication adherence and subsequent clinical inertia in type 2 diabetes glycemic management. Diabetes Care. 2007; 30(4):807-12.

6. Hardman TC, Dubrey SW. Development and potential role of type-2 sodiumglucose transporter inhibitors for management of type 2 diabetes. Diabetes Ther. 2011; 2(3):133-45.

7. Vallon V, Platt KA, Cunard R, Schroth J, Whaley J, Thomson SC, et al. SGLT2 mediates glucose reabsorption in the early proximal tubule. J Am Soc Nephrol. 2011; 22(1):104-12

8. Hummel CS, Lu C, Loo DD, Hirayama BA, Voss AA, Wright EM. Glucose transport by human renal Na+/D-glucose cotransporters SGLT1 and SGLT2. Am J Physiol Cell Physiol. 2011; 300(1):C14-21

9. Wright EM. Renal Na(+)-glucose cotransporters. Am J Physiol Renal Physiol. 2001; 280(1):F10-8

10. Ferrannini E, Ramos SJ, Salsali A, Tang W, List JF. Dapagliflozin monotherapy in type 2 diabetic patients with inadequate glycemic control by diet and exercise: a randomized, double-blind, placebo-controlled, phase 3 trial. Diabetes Care. 2010; 33(10):2217-24

11. Ferrannini E, Solini A. SGLT2 inhibition in diabetes mellitus: rationale and clinical prospects. Nat Rev Endocrinol. 2012; 8(8):495-502.

12. Hasan FM, Alsahli M, Gerich JE. SGLT2 inhibitors in the treatment of type 2 diabetes. Diabetes Res Clin Pract. 2014; 104(3):297-322.

13. List JF, Whaley JM. Glucose dynamics and mechanistic implications of SGLT2 inhibitors in animals and humans. Kidney Int Suppl. 2011; (120):S20-7.

14. Jabbour SA, Goldstein BJ. Sodium glucose co-transporter 2 inhibitors: blocking renal tubular reabsorption of glucose to improve glycaemic control in patients with diabetes. Int J Clin Pract. 2008; 62(8):1279-84.

15. Polidori D, Sha S, Mudaliar S, Ciaraldi TP, Ghosh A, Vaccaro N. Canagliflozin lowers postprandial glucose and insulin by delaying intestinal glucose absorption in addition to increasing urinary glucose excretion results of a randomized, placebo-controlled study. Diabetes Care. 2013; 36(8):2154-61

16. Marsenic $\mathrm{O}$. Glucose control by the kidney: an emerging target in diabetes. Am J Kidney Dis. 2009; 53(5):875-83

17. Monami M, Nardini C, Mannucci E. Efficacy and safety of sodium glucose co-transport- 2 inhibitors in type 2 diabetes: a meta-analysis of randomized clinical trials. Diabetes Obes Metab. 2014; 16(5):457-66.

18. List JF, Woo V, Morales E, Tang W, Fiedorek FT. Sodium-glucose cotransport inhibition with dapagliflozin in type 2 diabetes. Diabetes Care. 2009; 32(4):650-7.

19. Bailey CJ, Gross JL, Pieters A, Bastien A, List JF. Effect of dapagliflozin in patients with type 2 diabetes who have inadequate glycaemic control with metformin: a randomised, double-blind, placebo-controlled trial. Lancet. 2010; 375(9733):2223-33. 
20. Cefalu WT, Leiter LA, Yoon KH, Arias P, Niskanen L, Xie J, et al. Efficacy and safety of canagliflozin versus glimepiride in patients with type 2 diabetes inadequately controlled with metformin (CANTATA-SU): 52 week results from a randomised, double-blind, phase 3 non-inferiority trial. Lancet. $2013 ; 382(9896): 941-50$.

21. Bolinder J, Ljunggren Ö, Johansson L, Wilding J, Langkilde AM, Sjöström CD, et al. Dapagliflozin maintains glycaemic control while reducing weight and body fat mass over 2 years in patients with type 2 diabetes mellitus inadequately controlled on metformin. Diabetes Obes Metab. 2014; 16(2):159-69.

22. Mohler ML, He Y, Wu Z, Hwang DJ, Miller DD. Recent and emerging antidiabetes targets. Med Res Rev. 2009; 29(1):125-95.

23. Baker WL, Smyth LR, Riche DM, Bourret EM, Chamberlin KW, White WB. Effects of sodium-glucose co-transporter 2 inhibitors on blood pressure: a systematic review and meta-analysis. J Am Soc Hypertens. 2014; 8(4):262-75.e9.

24. Vasilakou D, Karagiannis T, Athanasiadou E, Mainou M, Liakos A, Bekiari E, et al. Sodium glucose cotransporter 2 inhibitors for type 2 diabetes: a systematic review and meta-analysis. Ann Intern Med. 2013; 159(4):262-74.

25. Cherney DZ, Perkins BA, Soleymanlou N, Har R, Fagan N, Johansen AE, et al. The effect of empagliflozin on arterial stiffness and heart rate variability in subjects with uncomplicated type 1 diabetes mellitus. Cardiovasc Diabetol. $2014 ; 13: 28$.

26. Fox CS, Coady S, Sorlie PD, D'Agostino RB Sr, Pencina MJ, Vasan RS, et al. Increasing cardiovascular disease burden due to diabetes mellitus: the Framingham Heart Study. Circulation. 2007; 115(12):1544-50.

27. Biessels GJ, Strachan MW, Visseren FL, Kappelle LJ, Whitmer RA. Dementia and cognitive decline in type 2 diabetes and prediabetic stages: towards targeted interventions. Lancet Diabetes Endocrinol. 2014; 2(3):246-55.

28. Lin B, Koibuchi N, Hasegawa Y, Sueta D, Toyama K, Uekawa K, et al. Glycemic control with empagliflozin, a novel selective SGLT2 inhibitor, ameliorates cardiovascular injury and cognitive dysfunction in obese and type 2 diabetic mice. Cardiovasc Diabetol. 2014; 13:148.

29. Madero M, Sarnak MJ, Wang X, Greene T, Beck GJ, Kusek JW, et al. Uric acid and long term outcomes in CKD. Am J Kidney Dis. 2009; 53(5):796-803

30. Davies MJ, Trujillo A, Vijapurkar U, Damaraju CV, Meininger G. Effect of canagliflozin on serum uric acid in patients with type 2 diabetes mellitus. Diabetes Obes Metab. 2015; 17(4):426-9.

31. Luippold G, Klein T, Mark M, Grempler R. Empagliflozin, a novel potent and selective SGLT-2 inhibitor, improves glycaemic control alone and in combination with insulin in streptozotocin-induced diabetic rats, a model of type 1 diabetes mellitus. Diabetes Obes Metab. 2012; 14(7):601-7.

32. Henry RR, Rosenstock J, Edelman S, Mudaliar S, Chalamandaris AG, Kasichayanula S et al. Exploring the potential of the SGLT2 inhibitor dapagliflozin in type 1 diabetes: a randomized, double-blind, placebocontrolled pilot study. Diabetes Care. 2015; 38(3):412-9.
33. Lamos EM, Younk LM, Davis SN. Empagliflozin, a sodium glucose cotransporter 2 inhibitor, in the treatment of type 1 diabetes. Expert Opin Investig Drugs. 2014; 23(6):875-82.

34. Gembardt F, Bartaun C, Jarzebska N, Mayoux E, Todorov VT, Hohenstein $\mathrm{B}$, et al. The SGLT2 inhibitor empagliflozin ameliorates early features of diabetic nephropathy in BTBR ob/ob type 2 diabetic mice with and without hypertension. Am J Physiol Renal Physiol. 2014; 307(3):F317-25.

35. Cherney DZ, Perkins BA, Soleymanlou N, Maione M, Lai V, Lee A, et al. Renal hemodynamic effect of sodium-glucose cotransporter 2 inhibition in patients with type 1 diabetes mellitus. Circulation 2014; 129(5):587-97.

36. Wanner C, Inzucchi SE, Lachin JM, Fitchett D, Eynatten MV, Mattheus M, et al. Empagliflozin and progression of kidney disease in type 2 diabetes. $\mathrm{N}$ Engl J Med. 2016; 375(4):323-34.

37. Barnett AH, Mithal A, Manassie J, Jones R, Rattunde H, Woerle HJ, et al. Efficacy and safety of empagliflozin added to existing antidiabetes treatment in patients with type 2 diabetes and chronic kidney disease: a randomised, double-blind, placebo-controlled trial. Lancet Diabetes Endocrinol. 2014; 2(5):369-84.

38. Tahir H, Wani A, Daruwalla V, Daboul N, Sagi J. Euglycemic diabetic ketoacidosis and severe acute kidney injury secondary to off labell use of sodium glucose cotransporter- 2 onhibitor in a type-1 diabetic patient. J Ayub Med Coll Abbottabad. 2015; 27(4):923-4.

39. Peters AL, Henry RR, Thakkar P, Tong C, Alba M. Diabetic ketoacidosis with canagliflozin, a sodium-glucose cotransporter 2 inhibitor, in patients with type 1 diabetes. Diabetes Care. 2016; 39(4):532-8.

40. Bilezikian JP, Watts NB, Usiskin K, Polidori D, Fung A, Sullivan D, et al. Evaluation of bone mineral density and bone biomarkers in patients with type 2 diabetes mellitus treated with canagliflozin, a sodium glucose co-transporter 2 inhibitor. J Clin Endocrinol Metab. 2016; 101(1):44-51.

41. Alba M, Xie J, Fung A, Desai M. The effects of canagliflozin, a sodium glucose cotransporter 2 inhibitor, on mineral metabolism and bone in patients with type 2 diabetes mellitus. Curr Med Res Opin. 2016; 32(8):1375-85.

42. Food and Drug Administration. Guidance for industry diabetes mellitus - evaluating cardiovascular risk in new antidiabetic therapies to treat type 2 diabetes. United States Department of Health and Human Services; 2008. Available from: https://www.fda.gov/downloads/Drugs/.../Guidances/ucm071627.pdf

43. Segui Díaz M. La empagliflozina reduce la mortalidad cardiovascular en pacientes diabéticos con eventos cardiovasculares previos. SEMERGEN. 2015; 42(5):e38-e9.

44. Guthrie RM. Sodium-glucose co-transporter 2 inhibitors and the potential for cardiovascular risk reduction in patients with type 2 diabetes mellitus. Postgrad Med. 2013; 125(3):21-32.

45. Zinman B, Wanner C, Lachin JM, Fitchett, D, Bluhmki E, Hantel S, et al.; EMPA-REG OUTCOME Investigators. Empagliflozin, cardiovascular outcomes, and mortality in type 2 diabetes. N Engl J Med 2015; 373(22):2117-28. 